\title{
Determinants of Iron Consumption among Pregnant Women in Southern Senegal
}

\author{
Khadim Niang1, Adama Faye ${ }^{1}$ Jean Augustin Diégane Tine¹, Fatou Bintou Diongue, Banda Ndiaye², \\ Mame Bineta Ndiaye ${ }^{2}$, Papa Ndiaye ${ }^{3}$, Anta Tal-Dia ${ }^{1}$
}

\author{
${ }^{1}$ Health and Development Institute (ISED) of Cheikh Anta Diop University of Dakar (UCAD), Dakar, Senegal \\ ${ }^{2}$ Micronutrient Initiative, Dakar, Senegal \\ ${ }^{3}$ Public Health Department of Gaston Berger University (UGB), Saint-Louis, Senegal \\ Email: khadimniang@outlook.com
}

How to cite this paper: Niang, K., Faye, A., Tine, J.A.D., Diongue, F.B., Ndiaye, B., Ndiaye, M.B., Ndiaye, P. and Tal-Dia, A. (2017) Determinants of Iron Consumption among Pregnant Women in Southern Senegal. Open Journal of Obstetrics and $G y$ necology, 7, 41-50.

http://dx.doi.org/10.4236/ojog.2017.71005

Received: December 5, 2016

Accepted: December 27, 2016

Published: December 30, 2016

Copyright $\odot 2017$ by authors and Scientific Research Publishing Inc. This work is licensed under the Creative Commons Attribution International License (CC BY 4.0).

http://creativecommons.org/licenses/by/4.0/

(c) (i) Open Access

\begin{abstract}
The anemia by iron deficiency is a public health problem. To palliate the multiple maternal and fetal consequences, the WHO recommends the iron supplementation during at least 90 days to all pregnant women. The goal of our study is to study the determinants of this consumption in the Kolda area (Senegal). It's the analytical cross-sectional study referred. We use the survey by clusters with 2 levels and it's about all of the women who gave birth in Kolda area between February 2013 and January 2014. The dependent variable was iron consumption during at least 90 days and the independents variables were grouped on personal factors, knowledge and practices. Data were collected during a personal interview face to face. We used logistic regression to identify the determinants of this consumption. The average age of women surveyed in 1442 was 25.5 years. They had knowledge of iron consumption (93\%) and the number of antennal consultation (ANC) (66\%). The prevalence of pregnant women who consumed iron at least for 90 days was $51 \%$. The factors associated with consumption were schooling ( $\mathrm{ORa}=2.49[1.54-4.03])$, health awareness $(\mathrm{ORa}=1.61$ [1.25 to 2.07]), knowledge about number of ANC $(\mathrm{ORa}=1.54$ [1.18 $2.00])$, councils on the benefits of iron ( $\mathrm{ORa}=2.66[1.77-4.00])$, the household wealth index $(\mathrm{ORa}=1.83$ [1.04 to 3.19]), number of $\mathrm{ANC}(\mathrm{ORa}=2.05[1.56-2.69])$, age pregnancy on the first ANC $(\mathrm{ORa}=2[1.47-2.7])$ and iron prescription $(\mathrm{ORa}=$ 1.64 [1.25 - 2.16]). The prevalence of iron consumption during at least 90 days is low in Kolda area (51\%); however, its determinants are identified; we can solve the problem by increasing communicate more about iron supplementation and antenatal consultation.
\end{abstract}

\section{Keywords}

Iron Consumption, Anemia, Pregnancy, Maternal Mortality, Senegal 


\section{Introduction}

Since late 1980s, the reduction of maternal deaths has been the main focus of international health agendas. Several international summits and conferences have taken this into account, including the Millennium Summit in 2000. One of the eight objectives of the Summit was to improve maternal health (MDG 5) and to reduce the ratio maternal mortality ratio by three-quarters between 1990 and 2015 [1].

Despite several progress in accessibility and availability of maternal health services, this ratio is still high and estimated at 450 maternal deaths per 100,000 live births (NV) in sub-Saharan Africa [2] [3]. In Senegal, there are 392 deaths per 100,000 NV against 723 deaths per $100,000 \mathrm{NV}$ in the region of Kolda where the health care situation is unsatisfactory [4].

According to the World Health Organization, 80\% of maternal deaths are due to severe bleeding, infections, hypertensive disorders during pregnancy and dystocia. The $20 \%$ would be related to indirect factors including anemia [2]. Prevention of this anemia requires iron supplementation since the only source of iron, which is the diet, and sometimes does not sufficiently meet the needs of the pregnant woman [5] [6] [7].

In 2011, in Senegal, the proportion of pregnant women who consumed iron for at least 90 days was $63 \%$. Factors of non-adherence to iron supplementation in pregnant women would be age, place of residence, educational attainment, household well-being, achievement of PNCS and accessibility, and the existence of certain cultural practices such as geophagy [8] [9] [10] [11]. These factors are not exhaustive and are not all described. Thus, the interest of this study is to help better know the determinants of iron consumption during pregnancy for at least 90 days in the Kolda region.

The aim of this work is to study the determinants of iron consumption for at least 90 days during pregnancy in the Kolda region.

\section{Framework, Tools and Methods}

\subsection{Framework}

This study was carried out in the region of Kolda, in the south of Senegal. It covers 13 $718 \mathrm{~km}^{2}$, i.e. $7 \%$ of the national territory [4]. The population of the region of Kolda recorded in 2013 is 633675 inhabitants with a density of 46 inhabitants per $\mathrm{km}^{2}$, a rate of urbanization of $26 \%$ and $74 \%$ of population living in rural areas [12].

The antenatal care utilization rate (ANC) was $101.6 \%$, the assisted delivery rate was $34.3 \%$ away from the target of $40 \%$. Contraceptive prevalence was low at $6.9 \%$ versus a national average of $12 \%$ and the rate of caesarean section was $1 \%$ [4]. The maternal mortality rate is 723 deaths per 100,000 new birth against a national average of 392 per 100,000 new birth [4] [12].

\subsection{Type of Study}

This was a cross-sectional, analytical study of the determinants of at least 90 days of iron use during pregnancy among women in the Kolda region. The study population represented the female population in child-bearing age in the Kolda region.

All women who gave birth in the last 12 months prior to the study, between February 
2013 and January 2014, were included, regardless of whether the delivery occurred in hospitals or at home. The refusal to participate and the absence of the woman at the time of collection constituted non-inclusion criteria.

The sample size was determined by the Schwartz formula, with an expected frequency of $63 \%$ and an accuracy of 5\%. Given that a two-level random survey would be conducted, the sample size, representative of each of the three health districts in the Kolda region, was estimated at 1413 individuals. The first level of sampling consisted of the basic draw of census districts from the sampling frame used by the National Agency for Statistics and Demography. The second level of sampling corresponded to the systematic sampling of households within pre-selected census districts.

\subsection{Ethical Considerations}

Participation in this study was voluntary after obtaining the informed consent of the woman. Anonymity was respected and the data collected were secured in order to preserve their confidentiality. The approval of the National Ethics Committee for Health Research in Senegal (CNERS) was obtained before the start of the field activities, as well as the necessary administrative authorizations.

\subsection{Data Collection Tool}

A previously tested and corrected questionnaire was administered to the women included in the study. This questionnaire included several aspects such as the personal characteristics, the knowledge of these women on the health of the mother and the child and finally the attitudes of supplementation. The woman's personal characteristics related to the age of the woman, her marital status, her professional activities and the economic level of the household (assessed through an assessment of incomes, assets and household size). The knowledge evaluated concerned prenatal consultations (number, importance...), prevention of anaemias and iron supplementation (importance, molecule to be used...). Prenatal consultation and supplementation practices were also assessed through prenatal consultations, accessibility of the PNC service, adherence to supplementation.

Data collection was carried out, over a period of 10 days, by three teams of ten investigators each, previously trained. The collection was done by face-to-face interviews between the interviewer and the woman at her home.

\subsection{Data Capture and Analysis}

The data thus collected were entered on Epi info version 3.5.3 and analyzed with software R.

A univariate analysis made it possible to describe the variables and to have their proportions for the qualitative variables or their averages and standard deviations for the quantitative variables.

The bivariate analysis made it possible to look for possible associations between the dependent variable (Iron consumption at least for 90 days) and the independent variables. Khi 2 and Fisher tests were used according to their applicability conditions with 
a significance threshold of 5\%. Multivariate analysis was done in creating a simple logistic regression model from bivariate analysis by integrating all variables with $p$-values below 0.25 into the model [13]. The simple logistic regression was performed for the determination of factors related to iron consumption for at least 90 days with successive adjustment on personal characteristics, resources and needs taking into account the conditions of applicability, the threshold of significance remaining fixed at 5\%.

\section{Results}

Among the 1442 women surveyed, the mean age was 25.48 with a standard deviation of 6.5 years. The minimum age for women was 14 , the maximum for 48 , with a proportion of $73 \%$ aged between 20 and 34 years.

The majority of women (Table 1) were uneducated (65\%), without income-generating activities (52\%), residing at a distance of less than $5 \mathrm{~km}$ from an antenatal clinic (55\% On the importance of PNCS (63\%) and iron supplementation (83\%) and knew iron as an anemia medication (93\%).

The study found that women did not perform at least the four recommended PNCS (68\%), were supplemented with iron during the last pregnancy (91\%) following a medical prescription (71\%), and observed Supplementation for at least 90 days (56\%) (Table 1).

Among women who had an income-generating activity, 52.4\% had consumed iron for at least 90 days, compared with $48.9 \%$ for women who did not. However, this difference was not statistically significant $(p=0.20)$. In bivariate analysis (Table 2$)$, iron consumption for at least 90 days was associated with personal characteristics (educational attainment, household well-being, distance from home to antenatal care, and woman's obstetric experience), knowledge of women (receiving advice on the realization of PNC and iron supplementation, recognition of iron as an anemia treatment) and attitudes (achievement of PNCS and the age of the first PNC, prescribing method iron).

Multivariate analysis showed that the factors that increased iron consumption for at least 90 days were higher levels of education, higher levels of household welfare, an income-generating activity for women, the prescription of iron supplementation by health personnel, the precociousness of the first prenatal consultation (PNC 1) and the realization of at least four PNCS (Table 3).

\section{Discussions}

The main limitation of this study is that the survey was conducted almost one year after delivery; which can be a source of memory bias. However the simplicity of the questions asked and the use of the notebooks of follow-up of the pregnancy made it possible to control it.

The results of our study show that $56 \%$ of women consumed iron for at least 90 days. The main determinants are personal characteristics (schooling, household well-being and income-generating activities) advice on iron intake and attitudes (method of prescribing iron, age of pregnancy at first NPC and number of NPCs performed). 
Table 1. Distribution of women who gave birth between February 2013 and January 2014 in the Kolda region according to their personal characteristics, knowledge and attitudes $(\mathrm{N}=1442)$.

\begin{tabular}{|c|c|c|c|}
\hline Variables & Terms and conditions & $\begin{array}{c}\text { Absolute } \\
\text { frequencies (n) }\end{array}$ & $\begin{array}{c}\text { Relative } \\
\text { frequencies (\%) }\end{array}$ \\
\hline \multirow{4}{*}{ Education level } & Not in school & 943 & 65 \\
\hline & Primary & 362 & 25 \\
\hline & Secondary & 135 & 9 \\
\hline & Superior & 2 & 1 \\
\hline \multirow{3}{*}{$\begin{array}{l}\text { Level of household } \\
\text { well-being }\end{array}$} & The poorest & 962 & 67 \\
\hline & Intermediate & 398 & 27 \\
\hline & The richest & 82 & 6 \\
\hline \multirow{5}{*}{$\begin{array}{c}\text { Existence of } \\
\text { income-generating } \\
\text { activities for women }\end{array}$} & Any & 747 & 52 \\
\hline & Crafts & 38 & 3 \\
\hline & Cash crops & 239 & 17 \\
\hline & Small business & 285 & 20 \\
\hline & Domesticated & 22 & 2 \\
\hline \multirow{4}{*}{$\begin{array}{l}\text { Distance between home } \\
\text { and antenatal care }\end{array}$} & Less than $5 \mathrm{~km}$ & 783 & 55 \\
\hline & Between 5 and $10 \mathrm{~km}$ & 271 & 19 \\
\hline & Between 10 and $15 \mathrm{~km}$ & 118 & 12 \\
\hline & More than $15 \mathrm{~km}$ & 175 & 12 \\
\hline \multirow{2}{*}{$\begin{array}{c}\text { Number of } \\
\text { deliveries of women }\end{array}$} & $<4$ & 767 & 52 \\
\hline & $\geq 4$ & 675 & 48 \\
\hline \multirow{3}{*}{$\begin{array}{l}\text { Receiving advice } \\
\text { on the } 4 \text { PNCS }\end{array}$} & Yes & 912 & 63 \\
\hline & No & 511 & 35 \\
\hline & Do not remember & 19 & 2 \\
\hline \multirow{2}{*}{$\begin{array}{c}\text { Knowledge of } \\
\text { anemia medications }\end{array}$} & Iron-folic acid & 1336 & 93 \\
\hline & Other & 106 & 7 \\
\hline \multirow{2}{*}{$\begin{array}{l}\text { Receiving advice } \\
\text { on taking iron }\end{array}$} & Yes & 1201 & 83 \\
\hline & No & 241 & 17 \\
\hline \multirow{2}{*}{$\begin{array}{c}\text { Number of PNCS } \\
\text { performed }\end{array}$} & $\geq 4 \mathrm{PNC}$ & 459 & 32 \\
\hline & $<4 \mathrm{PNC}$ & 983 & 68 \\
\hline \multirow{2}{*}{$\begin{array}{l}\text { Age of pregnancy } \\
\text { at CPN1 }\end{array}$} & $<3$ months & 326 & 52 \\
\hline & $\geq 3$ months & 307 & 48 \\
\hline \multirow{3}{*}{$\begin{array}{l}\text { Taking iron during } \\
\text { the last pregnancy }\end{array}$} & Yes & 1319 & 91 \\
\hline & No & 80 & 6 \\
\hline & Do not remember & 43 & 3 \\
\hline \multirow{3}{*}{$\begin{array}{l}\text { Prescription of iron } \\
\text { supplementation during } \\
\text { the last pregnancy }\end{array}$} & Yes & 1020 & 71 \\
\hline & Self-medication & 209 & 14 \\
\hline & Do not remember & 213 & 15 \\
\hline \multirow{3}{*}{$\begin{array}{l}\text { Number of iron } \\
\text { intake days }\end{array}$} & 0 - 59 days & 664 & 43 \\
\hline & $60-89$ & 18 & 1 \\
\hline & 90 days and more & 760 & 56 \\
\hline
\end{tabular}


Table 2. Characteristics, knowledge and attitudes of women who gave birth between February 2013 and January 2014 in the Kolda region and consumption of iron for at least 90 days.

\begin{tabular}{|c|c|c|c|}
\hline Variables & Terms and conditions & $\begin{array}{c}\text { Iron intake for } \\
\text { at least } 90 \text { days (\%) }\end{array}$ & $p$-value \\
\hline \multirow{3}{*}{ Education Level } & Not in school & 45.9 & \multirow{3}{*}{$<0.001$} \\
\hline & Primary & 53.9 & \\
\hline & Secondary/higher & 74.1 & \\
\hline \multirow{2}{*}{$\begin{array}{l}\text { Existence of income-generating } \\
\text { activities for women }\end{array}$} & Yes & 52.4 & \multirow{2}{*}{0.20} \\
\hline & No & 48.9 & \\
\hline \multirow{3}{*}{ Level of household well-being } & The poorest & 44.5 & \multirow{3}{*}{$<0.001$} \\
\hline & Intermediate & 61.6 & \\
\hline & The richest & 68.3 & \\
\hline \multirow{2}{*}{$\begin{array}{l}\text { Distance between home } \\
\text { and antenatal care }\end{array}$} & $<10 \mathrm{~km}$ & 53.2 & \multirow{2}{*}{0.001} \\
\hline & $\geq 10 \mathrm{~km}$ & 43.3 & \\
\hline \multirow{2}{*}{ Number of deliveries of women } & $<4$ & 55.2 & \multirow{2}{*}{0.002} \\
\hline & $\geq 4$ & 46.1 & \\
\hline \multirow{2}{*}{ Knowledge of anemia medications } & Iron-folic acid & 52.6 & \multirow{2}{*}{$<0.001$} \\
\hline & Other & 24.5 & \\
\hline \multirow{2}{*}{ Receiving advice on the 4 PNCs } & Yes & 58.6 & \multirow{2}{*}{$<0.001$} \\
\hline & No & 36.8 & \\
\hline \multirow{2}{*}{ Receiving advice on taking iron } & Yes & 56.5 & \multirow{2}{*}{$<0.001$} \\
\hline & No & 21.2 & \\
\hline \multirow{2}{*}{ Age of pregnancy at PNC 1} & $<3$ months & 70.7 & \multirow{2}{*}{$<0.001$} \\
\hline & $\geq 3$ months & 44.6 & \\
\hline \multirow{2}{*}{ Number of PNCs carried out } & $\geq 4$ visits & 67.1 & \multirow{2}{*}{$<0.001$} \\
\hline & $<4$ visits & 42.8 & \\
\hline \multirow{2}{*}{ Prescription of iron } & Yes & 56.6 & \multirow{2}{*}{$<0.001$} \\
\hline & Self-medication & 36.0 & \\
\hline
\end{tabular}

Table 3. Modeling factors related to iron consumption for at least 90 days in women who gave birth between February 2013 and January 2014 in the region of Kolda.

\begin{tabular}{cccc}
\hline Variables & $\begin{array}{c}\text { Terms and } \\
\text { conditions }\end{array}$ & $\begin{array}{c}\text { Model 1 } \\
\text { OR (95\% CI) }\end{array}$ & $\begin{array}{c}\text { Model 2 } \\
\text { OR (95\% CI) }\end{array}$ \\
\hline Education level & Not in school & 1 & 1 \\
& Primary & $1.17(0.89-1.54)$ & $1.16(0.88-1.54)$ \\
\hline $\begin{array}{c}\text { Existence of income } \\
\text { generating activities for women }\end{array}$ & No & 1 & $1.49(1.54-4.03)$ \\
\hline $\begin{array}{c}\text { Yevel of household well-being } \\
\text { Yes }\end{array}$ & The poorest & $1.2(0.95-1.52)$ & $1.28(1.10-1.63)$ \\
\hline $\begin{array}{c}\text { Intermediate } \\
\text { and antenatal care }\end{array}$ & $1.61(1.22-2.13)$ & $1.66(1.25-2.21)$ \\
\hline $\begin{array}{c}\text { Number of deliveries of } \\
\text { women }\end{array}$ & $\geq 10 \mathrm{~km}$ & $1.96(1.14-3.37)$ & $1.83(1.04-3.19)$ \\
\hline & $<10 \mathrm{~km}$ & $1.02(0.75-1.37)$ & $0.99(0.73-1.34)$ \\
\hline
\end{tabular}




\begin{tabular}{cccc} 
Continued & & & \\
\hline Knowledge of anemia medications & Other & 1 & 1 \\
& Iron-folic acid & $0.84(0.49-1.42)$ & $1.02(0.61-1.76)$ \\
\hline \multirow{2}{*}{ Receiving advice on the 4 PNCs } & No & 1 & 1 \\
\hline Receiving advice on taking iron & Yes & $1.3(0.99-1.7)$ & $1.13(0.88-1.53)$ \\
\hline Age of Pregnancy at PNC 1 & No & 1 & 1 \\
\hline Yes & $3(2.02-4.47)$ & $2.66(1.77-4.0)$ \\
\hline Number of PNCs carried out & $<3$ months & - & 1 \\
& $\geq 3$ months & & $2(1.47-2.7)$ \\
\hline Prescription of iron & $<4$ visits & - & 1 \\
& Yes visits & & $1.05(1.56-2.69)$ \\
\hline & Self-medication & & 1 \\
\hline
\end{tabular}

Our study limits the fact that the survey was conducted almost one year after women gave birth; which can be a source of bias information including flawing memorization. However, the precision of the collection tool avoided this type of bias. The main strengths of this study are its accuracy because of the relatively high sample size (1442 women surveyed) and the method of analysis that allowed for correcting confusing factors.

According to the World Health Organization, all pregnant women in developing countries with a high prevalence of anemia must consume iron for at least 90 days to prevent pregnancy anemia and improve pregnancy outcomes, as well as maternal and child health [14] [15] [16]. This recommendation is not fully respected. Thus, the proportion of pregnant women who consume iron for at least 90 days during pregnancy varies from country to country and from region to region within the same country.

The results reported here are those of a cross-sectional analytical study carried out in the region of Kolda in 1442 women who gave birth between February 2013 and January 2014. They reveal that $91 \%$ of women had consumed iron during their pregnancy, but the proportion who consumed it for at least 90 days was only $51 \%$. This low proportion has also been found in several developing countries such as Cambodia, Mali, Nepal and Indonesia, where they are respectively $47 \%, 28 \%, 20.7 \%$ and $40 \%$ [17] [18] [19] [20]. However, relatively high rates have also been observed in other developing countries such as Nigeria [21] and India [22] where the authors reported rates of $65.9 \%$ and $64.7 \%$, respectively. In Europe, studies of pregnant English women indicated that 70\% of these women adhered to iron supplementation [23] [24].

These prevalence differences across the world may be related to the sociodemographic characteristics of the study population or to whether or not prenatal care is available; However, Lacerte et al. in a study conducted in Cambodia stated that this is rather the consequence of the ineffectiveness of the implementation of prevention programs in place [19].

Several factors have been identified as associated with iron consumption for at least 90 days in pregnant women. Schooling, especially at the secondary or higher level, can 
positively influence this consumption. Indeed, in our study $74.1 \%$ of women who had this level of education had respected the appropriate duration of iron consumption and were 2.49 times more likely to respect it. Corresponding findings were found in Nepal [18] with an OR of 3.1, Nigeria [21] with an OR of 5.5 and Pakistan [25] with OR of 2.36. These results are similar to previous studies in the DHS where the authors found that women with a high level of education were likely to consume iron properly [8] [9] [17]. This may be explained by the fact that educated women have better access to health information, increasing their concern about their health and that of their future babies, but also have easier access to health information. Health services that provide iron.

Indeed, it is often through awareness that women receive information about health. Women of reproductive age who have attended health awareness sessions acquire knowledge that pushing them to adhere to the consumption of iron. In our study, nearly $60 \%$ of women met this criterion with ORa of 1.62 . Previous studies in Cambodia [19] and Sweden [26] have also reached similar conclusions.

According to Khanal et al., counseling about the benefits of consuming iron throughout pregnancy and postpartum may influence women to consume it [18]. This hypothesis is verified in our study where women who received these tips were 2.66 times more likely to consume iron for at least 90 days. These results are similar to those found by several authors, such as in Senegal [27], India [28], Ethiopia [29] and Viet Nam [30]. This suggests that IEC interventions and especially the quality of information provided to women can play an important role in accessing health care facilities and hence in the consumption of iron for at least 90 days.

The results of our study showed that the higher the level of economic well-being of the household, the more likely a woman is to consume iron properly. Superposable results have been found in the literature [8] [9] [17] [21] [25] [28]. On the other hand, studies in Denmark and Ethiopia have shown contrary results [29] [30]. This may be explained by the fact that women from wealthy backgrounds may consider themselves to be less vulnerable to anemia and therefore have poor compliance.

Iron supplementation is an integral part of the refocused PNC and it is during these PNCS that midwives reiterate and reinforce the interest in iron use throughout pregnancy among women. The high percentages found in women who had early PNC (70.7\%) and those with 4 or more PNCS (67\%) were justified and were similar to those reported in several studies [19] [27].

We know that the prescription of iron is the proof of the contact between the pregnant woman and the health professional. At present, the association between prescription and iron consumption is not documented in the literature, but we have shown by showing that the chance of consuming iron for at least 90 days was multiplied by 1.64 Women with a prescription in iron than in women in self-medication.

\section{Conclusions}

The use of iron for at least 90 days during pregnancy remains an effective means of controlling serious deficiency anemia and thus reducing maternal and infant morbidity and mortality. 
The results of this study reveal that this consumption is still low (51\%) in the Kolda region, where it is influenced by a number of factors, including women's education, awareness of women in health, counseling on the benefits of iron intake during pregnancy, the level of well-being of the household and the woman's attitudes (number of PNCS performed, age of pregnancy at the first PNC and mode of prescription of iron).

Knowledge of these determinants may contribute to the development of good practice guidelines for reproductive health interventions to improve the prevalence of iron use for at least 90 days during pregnancy.

\section{Acknowledgements}

Acknowledgment to the Micronutrient Initiative that funded this study and to all Kolda women who agreed to participate in this survey.

\section{Conflict}

No conflict of interest to declare.

\section{References}

[1] General Assembly of the United Nations (2000) Resolution 55/2 on the Millennium Declaration. United Nations.

[2] WHO, UNICEF, UNFPA and the World Bank (2007) Maternal Mortality in 2005. World Health Organization, Geneva, 16-18.

[3] United Nations (2015) Millennium Development Goals-Report 2014. United Nations.

[4] National Agency of Statistics and Demography (2011) Regional Service of Statistics and Demography of Kolda. Economic and Social Regional Situation 2010. Ministry of Economy and Finance of Senegal, 65-78.

[5] Leslie, J. (1991) Women's Nutrition: The Key to Improving Family Nutrition in Developing Countries? Health Policy and Planning, 6, 1-19. https://doi.org/10.1093/heapol/6.1.1

[6] Lemonnitv, D. and Ingenblwk, C.I.Y. (1989) Nutritional Deficiencies in Developing Countries. Third Day of the GIRM. KARTHALA. ACCT, Paris, 280-284.

[7] Ayoubi, J.M., Hirt, R., Badiou, W., Hininger-Favier, I., Zraik-Ayoubi, F., Berrebi, A. and Pons, J.C. (2012) Nutrition and Pregnant Woman. EMC Obstetric Gynecology, 5-7.

[8] Ministry of Health. Multiple Indicator Demographic and Health Survey SENEGAL-20102011. Final Report, 182-186.

[9] Ministry of Health. Demographic and Health Survey-DRC-2007. Final Report, 179-184.

[10] Collignon, R. (1992) Concerning the Disturbances of the Behavior of the Pica of Physicians to the Geophagy of Geographers, Travelers and Ethnologists. Psychopathologie Africaine, XXIV, 385-396.

[11] Strobe, L.M. (2003) Geophagie. IFMT OCT, 1-34.

[12] Ministry of Planning (2013) General Census of Population and Housing, Agriculture and Livestock. Interim Report, ANSD.

[13] Collett, D. (2003) Modeling Binary Data. CRC Press, London, 387 p.

[14] Sandalinas, F. (2004-2005) Micronutrients in Pregnant Women: An Important Ally? Situation and Strategies for Addressing Gaps in Developing Countries. Bibliographic Research Report, 21.

[15] WHO (2009) Role of Weekly Supplementation of Iron and Folic Acid in Women of Childbearing Age to Promote Optimal Maternal and Child Health. World Health Organization, 
Geneva.

[16] WHO/NMH/NHD/MNM (2009) Role of Weekly Supplementation of Iron and Folic Acid in Women of Childbearing Age to Promote Optimal Maternal and Child Health.

[17] Ministry of Health (2006) Demographic and Health Survey-MALI. Final Report, 167-168.

[18] Khanal, V., Adhikari, M. and Karkee, R. (2014) Low Compliance with Iron-Folate Supplementation among Postpartum Mothers of Nepal: An Analysis of Nepal. Demographic and Health Survey 2011. Community Health, 39, 606-613. https://doi.org/10.1007/s10900-013-9806-6

[19] Lacerte, P., Pradipasen, M., Temcharoen, P., Imamee, N. and Vorapongsathorn, T. (2011) Determinants of Adherence to Iron/Folate Supplementation in Pregnancy in Two Provinces in Cambodia. Asia Pacific Journal of Public Health, 23, 315-323. https://doi.org/10.1177/1010539511403133

[20] Schultink, W., van der Ree, M., Matulessi, P. and Gross, R. (1993) Low Compliance with an Iron-Supplementation Program in Jakarta, Indonesia. The American Journal of Clinical Nutrition, 57, 135-139.

[21] Ugwu, E.O., Olibe, A.O., Obi, S.N. and Ugwu, A.O. (2014) Determinants of Compliance with Iron Supplementation among Pregnant Women in Enugu, Southeastern Nigeria. $\mathrm{Ni}$ gerian Journal of Clinical Practice, 17, 608-612. https://doi.org/10.4103/1119-3077.141427

[22] Mithra, P., Unnikrishnan, B., Rekha, T., Nithin, K., Mohan, K., Kulkarni, V., Kulkarni, V. and Agarwal, D. (2013) Compliance with Iron-Folic Acid (IFA). African Health Sciences, 13, 880-885. https://doi.org/10.4314/ahs.v13i4.3

[23] Afifi, A.M., Banwell, G.S., Bennison, R., et al. (1966) Simple Test for Ingested Their Iron in Hospital and Domicily Practice. BMJ, 1, 1021-1022.

https://doi.org/10.1136/bmj.1.5494.1021

[24] Bonnar, J., Goldberg, A. and Smith, J.A. (1969) Do Pregnant Women Take Their Iron? Lancet, 1, 457-458. https://doi.org/10.1016/S0140-6736(69)91492-5

[25] Nisar, B.Y., Dibley, J.M. and Mir, A.M. (2014) Factors associated with Non-Use of Antenatal Iron and Folic Acid Supplements among Pakistani Women: A Cross Sectional Household Survey. BMC Pregnancy and Childbirth, 14, 305. https://doi.org/10.1186/1471-2393-14-305

[26] Wulff, M. and Ekstrom, E. (2003) Iron Supplementation in Pregnancy in Sweden: To What Extent Is the National Recommendation Followed? Acta Obstetricia et Gynecologica Scandinavica, 82, 628-635. https://doi.org/10.1034/j.1600-0412.2003.00186.x

[27] Seck, B.C. and Jackson, R. (2007) Determinants of Compliance with Iron Supplementation among Pregnant Women in Senegal. Public Health Nutrition, 11, 596-605.

[28] Pal, P.P., Sharma, S., Sarkar, T.K. and Mitra, P. (2013) Iron and Folic Acid Consumption by the Ante-Natal Mothers in a Rural Area of India in 2010. International Journal of Preventive Medicine, 4, 1213-1216.

[29] Gebremedhin, S., Aregash, S., Mamo, G., Moges, T. and Assefa, T. (2014) Coverage, Compliance and Factors Associated with Use of Iron Supplementation during Pregnancy in Eight Rural Districts of Ethiopia: A Cross-Sectional Study. BMC Public Health, 14, 607. https://doi.org/10.1186/1471-2458-14-607

[30] Knudsen, V.K., Hansen, H.S., Ovesen, L., Mikkelsen, T.B. and Olsen, S.F. (2007) Iron Supplement Use among Danish Pregnant Women. Public Health Nutrition, 10, 1104-1110. https://doi.org/10.1017/S136898000769956X 
Submit or recommend next manuscript to SCIRP and we will provide best service for you:

Accepting pre-submission inquiries through Email, Facebook, LinkedIn, Twitter, etc. A wide selection of journals (inclusive of 9 subjects, more than 200 journals)

Providing 24-hour high-quality service

User-friendly online submission system

Fair and swift peer-review system

Efficient typesetting and proofreading procedure

Display of the result of downloads and visits, as well as the number of cited articles Maximum dissemination of your research work

Submit your manuscript at: http://papersubmission.scirp.org/

Or contact ojog@scirp.org 